\title{
CORRIGENDUM
}

\section{A PHGDH inhibitor reveals coordination of serine synthesis and one-carbon unit fate}

Michael E Pacold, Kyle R Brimacombe, Sze Ham Chan, Jason M Rohde, Caroline A Lewis, Lotteke J Y M Swier, Richard Possemato, Walter W Chen, Lucas B Sullivan, Brian P Fiske, Steve Cho, Elizaveta Freinkman, Kıvanç Birsoy, Monther Abu-Remaileh, Yoav D Shaul, Chieh Min Liu, Minerva Zhou, Min Jung Koh, Haeyoon Chung, Shawn M Davidson, Alba Luengo, Amy Q Wang, Xin Xu, Adam Yasgar, Li Liu, Ganesha Rai, Kenneth D Westover, Matthew G Vander Heiden, Min Shen, Nathanael S Gray, Matthew B Boxer \& David M Sabatini

Nat. Chem. Biol. 12, 452-458 (2016); received 16 December 2015; accepted 24 March 2016; published online 25 April 2016; corrected after print 28 June 2016

In the version of this article initially published, the author omitted some funding sources: NIH (R03 DA034602-01A1, R01 CA129105, R01 CA103866, and R37 AI047389 to D.M.S.) and the US Department of Defense (W81XWH-14-PRCRP-IA to D.M.S.). The error has been corrected in the HTML and PDF versions of the article. 